\title{
Support-induced compensation effects in H/D exchange of cyclopentane
}

\author{
M.K. Oudenhuijzen, J.A. van Bokhoven, and D.C. Koningsberger* \\ Department of Inorganic Chemistry and Catalysis, PO Box 80083, 3508 TB Utrecht, The Netherlands
}

Received 19 November 2002; revised 28 April 2003; accepted 28 April 2003

\begin{abstract}
The exchange of hydrogen for deuterium (H/D exchange) in cyclopentane was measured for Pt catalysts with supports of various acidity. With an earlier developed Monte-Carlo model the contributions of the various possible intermediates in the H/D exchange can directly be measured. It was shown that the activity and the selectivity in the H/D exchange over the supported Pt catalysts strongly depend on the support acid/base properties. The activities of the various catalysts show a compensation effect. The compensation effect can directly be correlated to the contribution of the various exchange mechanisms, which proceed via different intermediates. The contribution of each intermediate depends on the electronic properties of the Pt particles, which in turn depend on the support acidity. This shows that the compensation effect is caused by support-induced changes in the adsorption modes of cyclopentane.
\end{abstract}

(C) 2003 Elsevier Inc. All rights reserved.

Keywords: H/D exchange; Cyclopentane; Reaction kinetics; Pt catalyst; Compensation effect; Metal-support interaction; Isokinetic relation

\section{Introduction}

The influence of the support acid/base properties on the catalytic properties of supported metal particles has been studied extensively $[1,2]$. It has been established that the rate of hydrogenolysis and hydrogenation over supported $\mathrm{Pt}$ particles increases with the acidity of oxidic supports [3,4]. A large amount of work has been dedicated to relate changes in catalytic properties to changes in the electronic properties of the Pt particles [5-10]. The support is believed to interact with the Pt particles via the oxygen atoms of the oxidic supports. In line with the definition of Lewis acidity, acidic supports are associated with a low-electron richness on the support oxygen atoms, whereas basic supports are associated with a high-electron richness. Recently, based on the results of atomic X-ray absorption fine structure spectroscopy (AXAFS) and ab initio multiple scattering calculations, it was found that a lower electron richness of the support oxygen atoms leads to a higher ionization potential of the Pt particles. At the same time, a charge rearrangement from within the Pt particle toward the metal-support interface was observed for acidic supports [10-12]. If the relation between support material and changes in activity/selectivity is well

\footnotetext{
* Corresponding author.

E-mail address: d.c.koningsberger@chem.uu.nl

(D.C. Koningsberger).
}

understood, it promises the prospect of tailor-made catalysts. However, there is a lot of discussion on the relations between support material and electronic properties on one hand and the catalytic properties on the other. The direct relation between the changes in electronic properties and its effect on the catalytic properties is not well understood.

Thus, the need for a good test reaction is obvious. An important feature for a proper test reaction is that it should be metal-catalyzed only. The isotopic exchange of hydrogen with deuterium in hydrocarbons (H/D exchange) is a typical metal-catalyzed reaction [13-16]. During H/D exchange, hydrogen atoms of a hydrocarbon are replaced by deuterium atoms. The advantage of H/D exchange of cyclopentane (CP) as a test reaction is that its product distribution gives direct information about the different modes of adsorption of the intermediates during the reaction. These adsorption modes are proposed to be dependent on the electronic properties of the metal [16-18].

In order to fully understand the H/D exchange mechanism of $\mathrm{CP}$, the kinetics, selectivities and adsorption modes of $\mathrm{CP}$ in the H/D exchange were studied in detail in an earlier paper [19]. It was shown that the D1 product is produced by the exchange of a single hydrogen atom via a $\sigma$-bonded $\eta^{1}$-cyclopentyl intermediate (called $\sigma-\eta^{1}$, Fig. 1A). The D2D5 products consist of cyclopentane with deuterium atoms all located on a single side of the ring, and is produced via a rotation mechanism of a $\pi$-bonded $\eta^{2}$-cyclopentene 


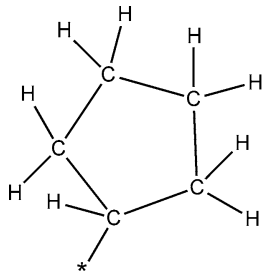

(A)

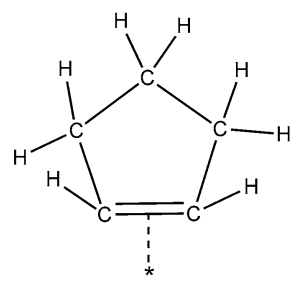

(C)

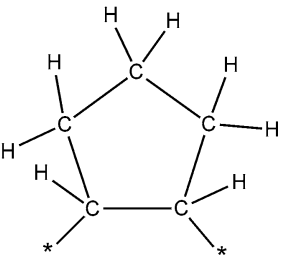

(B)

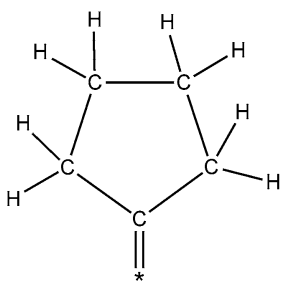

(D)
Fig. 1. Different adsorbed intermediates, leading to different products. (A) $\sigma$-Bonded $\eta^{1}$-cyclopentyl $\left(\sigma-\eta^{1}\right)$, leading to D1; (B) a double $\sigma$-bonded $\alpha, \beta-\eta^{2}$-cyclopentyl (d- $\left.\sigma-\eta^{2}\right)$; and (C) $\pi$-bonded $\eta^{2}$-cyclopentene $\left(\pi-\eta^{2}\right)$, both leading to D2-D5 products, and (D) double $\sigma$-bonded $\eta^{1}$-cyclopentylidene $\left(\mathrm{di}-\sigma-\eta^{1}\right)$ leading to rollover.

(called $\pi-\eta^{2}$, Fig. 1C) $[16,20]$. The D2 product can also be formed via a second intermediate, a double $\sigma$-bonded $\alpha, \beta-\eta^{2}$-cyclopentyl (di- $\sigma-\eta^{2}$, Fig. 1B) [21]. With the D6D10 products, the $\mathrm{CP}$ must be rolled over from one side of the ring to the other, leading to the possibility that the atoms on the second side of the ring are also exchanged. The only species that can roll over is the $\pi-\eta^{2}$ intermediate via a double $\sigma$-bonded $\eta^{1}$-cyclopentylidene (di- $\sigma-\eta^{1}$, Fig. 1D). A Monte-Carlo model was developed, which can be used to accurately determine the relative contributions of the abovenoted intermediates. The Monte-Carlo model reveals that the multiplicity parameter as defined in the literature does not represent the relative contribution of each intermediate, although it has been generally used for this purpose [22]. In addition to an understanding of the selectivity, also a kinetic model for the understanding of observed orders and reaction rates was developed [19].

This paper focuses on the influence of the support on the $\mathrm{H} / \mathrm{D}$ exchange of $\mathrm{CP}$ over supported Pt catalysts. It will be shown that kinetics and selectivities are largely affected by the support material. Particle size effects are separated from support effects. The activity shows a compensation effect, and the apparent activation energy and pre-exponential factor show an isokinetic relationship [23,24]. This can be explained by different adsorption modes of the $\mathrm{CP}$ on the metallic Pt surface. The change in adsorption modes is attributed to a change in the electronic structure of the Pt particles, which in turn is induced by changes in the acid/base properties of the support.

\section{Methods}

\subsection{Catalyst preparation}

Several supported Pt catalysts were prepared. The supports used are $\mathrm{Mg}$ hydrotalcite $(\mathrm{HT}), \mathrm{SiO}_{2}$, amorphous $\mathrm{SiO}_{2}-\mathrm{Al}_{2} \mathrm{O}_{3}$ (ASA), and LTL zeolite. The support characteristics are shown in Table 1. The acidity of the LTL zeolite was varied by either impregnating a K-LTL zeolite with $\mathrm{KNO}_{3}(\mathrm{aq})$, or exchanging it with $\mathrm{NH}_{4} \mathrm{NO}_{3}$ to give $\mathrm{K} / \mathrm{Al}$ ratios ranging from 0.47 to 1.53 . The zeolites were calcined at $225^{\circ} \mathrm{C}$ and analyzed for $\mathrm{K}$ and $\mathrm{Al}$ contents. The catalysts are designated LTL $\left[{ }^{*}{ }^{* *}\right]$ with ${ }^{*}{ }^{* *}$ representing the $\mathrm{K} / \mathrm{Al}$ ratio. The HT support was prepared and activated (calcination at $450^{\circ} \mathrm{C}$ in $\mathrm{N}_{2}$ ) according by Roelofs et al. [25].

Pt was added by incipient wetness impregnation (LTL zeolites, $\mathrm{Pt} / \mathrm{SiO}_{2}$ [big] and $\mathrm{Pt} / \mathrm{ASA}$ [11.3]) or ion exchange $\left(\mathrm{Pt} / \mathrm{SiO}_{2}\right.$ [small], using a $\mathrm{pH}$ of $\sim 9$, and $\mathrm{Pt} / \mathrm{ASA}$ [2.5]) of an aqueous $\mathrm{Pt}\left(\mathrm{NH}_{3}\right)_{4}\left(\mathrm{NO}_{3}\right)_{2}$ solution, resulting in a $1 \mathrm{wt} \%$ $\mathrm{Pt} / \mathrm{LTL}$ catalyst. Pt was added to HT by adding $\mathrm{H}_{2} \mathrm{PtCl}_{6}$ to the hydrotalcite support during the rehydration procedure following the activation. The Pt loading after ion exchange was determined with AAS.

Table 1

The characteristics of the supports

\begin{tabular}{|c|c|c|c|c|c|c|}
\hline \multirow[t]{2}{*}{ Support } & \multirow[t]{2}{*}{$\mathrm{Si} / \mathrm{Al}$} & \multirow{2}{*}{$\begin{array}{l}\text { No. of acid sites } \\
\quad(\mathrm{mmol} / \mathrm{g})^{\mathrm{a}}\end{array}$} & \multirow{2}{*}{$\begin{array}{l}\text { BET surface } \\
\text { area }\left(\mathrm{m}^{2} / \mathrm{g}\right)\end{array}$} & \multicolumn{2}{|c|}{ Pore volume $(\mathrm{ml} / \mathrm{g})$} & \multirow{2}{*}{$\begin{array}{l}\text { Average pore } \\
\text { diameter }(\mathrm{nm})^{\mathrm{b}}\end{array}$} \\
\hline & & & & Total & Micropore & \\
\hline $\mathrm{SiO}_{2}$ & n.a. & n.a. & 405 & 1.10 & 0 & $25( \pm 15 \mathrm{~nm})$ \\
\hline ASA [2.5] & 2.5 & 1.2 & 355 & 0.59 & 0 & $7( \pm 2 \mathrm{~nm})$ \\
\hline ASA [11.3] & 11.3 & 0.28 & 321 & 0.50 & 0 & $5( \pm 1 \mathrm{~nm})$ \\
\hline K-LTL & 3.0 & $\begin{array}{l}\mathrm{K} / \mathrm{Al}=0.47: 1.76 \\
\mathrm{~K} / \mathrm{Al}=0.82: 0.58 \\
\mathrm{~K} / \mathrm{Al}>1: \text { none }\end{array}$ & & 0.25 & 0.11 & $\begin{array}{l}0.71^{\mathrm{c}} \\
1.30\end{array}$ \\
\hline Hydrotalcite & $\mathrm{Mg} / \mathrm{Al}=3.0$ & n.a. & 105 & 0.57 & 0.00 & $18( \pm 3 \mathrm{~nm})$ \\
\hline
\end{tabular}

a The number of acid sites for the ASA was determined with the combined thermographic analysis and temperature-programmed desorption of isopropylamine. For the LTL zeolites it was calculated based upon crystallographic data [29].

b Determined from the $\mathrm{N}_{2}$ desorption plot, according to the Broekhoff I method for $\mathrm{CeO}_{2}-3 \mathrm{H}_{2} \mathrm{O}$. The values between brackets represent the distribution in pore diameter.

c LTL zeolites have pores in a single direction along the [001] axis [29]. The pores are constructed of cages with a diameter of $13 \AA$, and are interconnected with 12-membered rings with a diameter of $7.1 \AA$ A. 

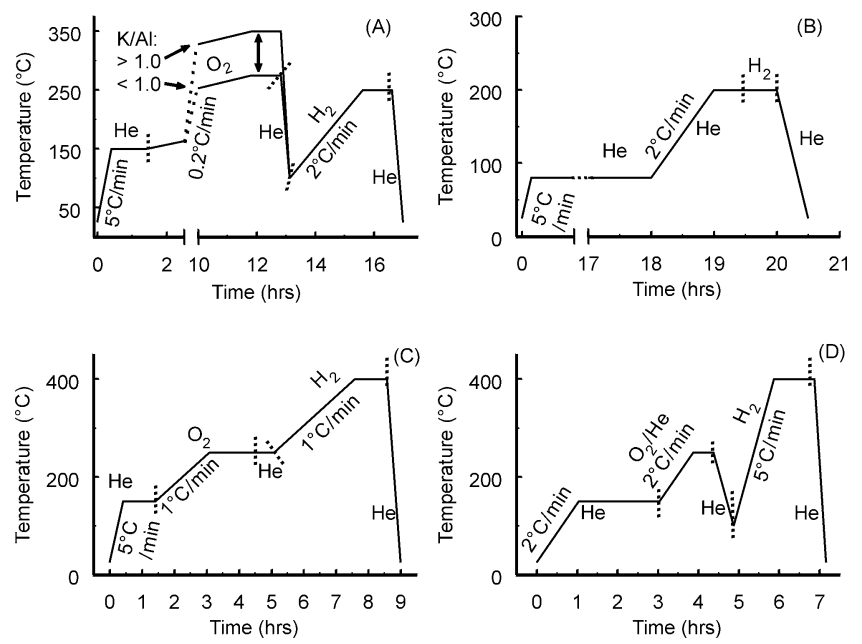

Fig. 2. The calcination-reduction schemes for the various catalysts: (A) for the Pt/LTL catalysts, (B) for Pt/HT, (C) for $\mathrm{Pt} / \mathrm{SiO}_{2}$ [big], (D) $\mathrm{Pt} / \mathrm{SiO}_{2}$ [small] and Pt/ASA. Typical GHSV values range from $7000 \mathrm{~h}^{-1}\left(\mathrm{SiO}_{2}\right.$, ASA, and HT) to $25,000 \mathrm{~h}^{-1}$ (LTL).

These catalyst precursors were all calcined and prereduced. For the calcination/reduction, a sieve fraction $(225<$ $d_{\mathrm{p}}<450 \mu \mathrm{m}$ ) was placed in a downflow fixed-bed reactor. Details of the pretreatment are given in Fig. 2. The prereduced catalysts were stored in air. The Pt particle size was determined by $\mathrm{H}_{2}$ chemisorption, high-resolution transmission electron microscopy, and EXAFS analysis. Details of $\mathrm{H}_{2}$ chemisorption [26], HRTEM [27] and EXAFS [26] are given elsewhere.

\section{2. $H / D$ exchange of cyclopentane}

\subsubsection{Experiments}

Details of the H/D exchange experiments are described elsewhere [19]. A downflow fixed-bed reactor (diameter of $4 \mathrm{~mm}$ ) was loaded with $\sim 5-10 \mathrm{mg}$ of the catalyst and diluted with $60 \mathrm{mg}$ of $\mathrm{SiO}_{2}$, both with a sieve fraction of $90<d_{\mathrm{p}}<150 \mu \mathrm{m}$. The basic catalysts (Pt/HT and Pt/LTL $[\mathrm{K} / \mathrm{Al}>1]$ showed extremely low activities, and the reactor was loaded with 70-90 mg pure catalyst.

The catalyst was prereduced for $1 \mathrm{~h}$ at $200^{\circ} \mathrm{C}(\mathrm{Pt} / \mathrm{HT})$, $300{ }^{\circ} \mathrm{C}\left(\mathrm{LTL}\left[{ }^{*}{ }^{* *}\right]\right)$, or $400{ }^{\circ} \mathrm{C}\left(\mathrm{Pt} / \mathrm{SiO}_{2}\left[{ }^{* *}\right]\right.$ and $\mathrm{Pt} / \mathrm{ASA}$ $\left.\left[{ }^{*}{ }^{* *}\right]\right)$ in hydrogen. The catalyst was cooled down in $50 \%$ $\mathrm{D}_{2}$ in Ar to $75^{\circ} \mathrm{C}$. Typical HD experiments were performed at $75^{\circ} \mathrm{C}$ at atmospheric pressure, with $P_{\mathrm{D}_{2}}=0.5$ bar, $P_{\mathrm{CP}}=$ 0.025 bar (resulting in $\mathrm{D} / \mathrm{H}=20$ ) and $P_{\mathrm{Ar}}=0.475$ bar, a GHSV of $7200 \mathrm{~h}^{-1}$ and conversions below $10 \%$ with no significant side reactions. It was checked that internal and external diffusion limitations were absent. Therefore, the observed kinetics and selectivities reflect the ture, intrinsic values of the catalysts.

\subsubsection{Analysis of the selectivity: the Monte-Carlo model}

In an earlier paper [19] a Monte-Carlo model was developed, which was used to accurately determine the relative contributions of the various intermediates shown in Fig. 1.
This Monte-Carlo model also reveals the true number of rotations each $\pi-\eta^{2}$ intermediate experiences, giving the real number of exchange steps. For example, a CP molecule observed as $\mathrm{C}_{5} \mathrm{H}_{5} \mathrm{D}_{5}$ has not only exchanged $5 \mathrm{H}$ atoms for 5 $\mathrm{D}$ atoms, but the introduced $\mathrm{D}$ atoms can also be exchanged for other D atoms. This D-D exchange cannot be directly measured, but is determined by this Monte-Carlo model.

\subsubsection{Analysis of reaction rates and orders}

The turnover frequency (TOF) is defined as the number of molecules CP that is converted per Pt surface atom per second. The number of accessible Pt surface atoms is based on the total amount of hydrogen chemisorbed. Orders in CP and $\mathrm{D}_{2}$ were determined by varying the applicable partial pressures while the total flow was kept constant.

Activation energies were determined by heating the catalyst 4-5 times from 65 to $90^{\circ} \mathrm{C}$. The following form of Arrhenius formula was used,

$\mathrm{TOF}=A_{\mathrm{app}} \mathrm{e}^{-E_{\mathrm{act}, \mathrm{app}} / R T}$,

where TOF is the turnover frequency, mol CP converted per mol surface $\mathrm{Pt}$, per second; $E_{\text {act, app }}$, the apparent activation energy $(\mathrm{kJ} / \mathrm{mol}) ; T$, the reaction temperature $(\mathrm{K})$; and $A_{\text {app}}$, the pre-exponential factor.

It was shown that the reaction rate can be modeled with the following reactions and corresponding rates [19]:

(I) $\mathrm{C}_{5} \mathrm{H}_{10}(\mathrm{~g})+* \stackrel{K_{1}}{\longleftrightarrow} \mathrm{C}_{5} \mathrm{H}_{10}(*)$,

(II) $\mathrm{D}_{2}(\mathrm{~g})+2^{*} \stackrel{K_{2}}{\longleftrightarrow} 2 \mathrm{D}(*)$,

(IIIA) $\mathrm{C}_{5} \mathrm{H}_{10}(*)+* \stackrel{k_{+3}}{\longleftrightarrow} \mathrm{C}_{5} \mathrm{H}_{9}(*)+\mathrm{H}\left(^{*}\right)$,

(IIIB) $\mathrm{C}_{5} \mathrm{H}_{n} \mathrm{D}_{9-n}(*)+\mathrm{D}\left(^{*}\right) \stackrel{k_{-3}}{\longleftrightarrow} \mathrm{C}_{5} \mathrm{H}_{n} \mathrm{D}_{10-n}(*)$

leading to a reaction rate $R$ given by

$R=r_{-3}=\frac{k_{-3} K_{1} K_{3} P_{\mathrm{CP}}}{\left(1+K_{1} P_{\mathrm{CP}}+\frac{K_{1} K_{3} P_{\mathrm{CP}}}{\sqrt{K_{2} P_{\mathrm{D}_{2}}}}+\sqrt{K_{2} P_{\mathrm{D}_{2}}}\right)^{2}}$,

where it assumed that $\mathrm{H}_{2}$ and $\mathrm{D}_{2}$ are chemically similar and thus $\left.\mathrm{H}^{*}\right)$ is also similar to $\mathrm{D}\left(^{*}\right)$ and $\mathrm{C}_{5} \mathrm{H}_{n} \mathrm{D}_{9-n}\left(^{*}\right)$ similar to $\mathrm{C}_{5} \mathrm{H}_{9}\left({ }^{*}\right)$, and thus $r_{+3}$ and $r_{-3}$ are equal in a steady-state reaction.

The observed orders in $\mathrm{CP}$ and $\mathrm{D}_{2}$ depend on the equilibrium constants $K_{1}, K_{2}$, and $K_{3}$, and in principle can be anything between +1 and -1 for $\mathrm{CP}$ and between 0 and -1 for $\mathrm{D}_{2}$. The selectivity in the H/D exchange is determined in a process after the rate-determining step.

The activation energy for the rollover reaction was determined from the above-noted Monte-Carlo-based method [19]: the Monte-Carlo method was used to accurately determine the contribution of the $\pi-\eta^{2}$ intermediate leading to D2-D10 and the amount of this $\pi-\eta^{2}$ intermediate that rolls over, giving D6-D10. The ratio of the two intermediates indicates how much of the $\pi-\eta^{2}$ intermediate rolls over via the di $-\sigma-\eta^{1}$ intermediate. This rollover is an activated mechanism, and by measuring the amount of rollover as a 
Table 2

The results of $\mathrm{H}_{2}$ chemisorption, HRTEM, and EXAFS analysis for the reduced Pt catalysts

\begin{tabular}{|c|c|c|c|c|c|c|c|}
\hline \multirow{2}{*}{$\begin{array}{l}\text { Catalyst, } \\
\mathrm{Pt} /\end{array}$} & \multicolumn{3}{|c|}{$\mathrm{H} / \mathrm{Pt}$} & \multirow{2}{*}{$\begin{array}{c}\text { Diameter }(\mathrm{nm}, \pm 0.2) \\
(\text { HRTEM })\end{array}$} & \multirow[t]{2}{*}{$N_{\mathrm{PtPt}}$} & \multirow{2}{*}{$N_{\mathrm{Pt}-\mathrm{O}}$} & \multirow{2}{*}{$\begin{array}{l}\text { Estimated } \\
\text { No. atoms }\end{array}$} \\
\hline & Weak & Strong & Total & & & & \\
\hline LTL [0.47, small] & 0.42 & 0.64 & 1.07 & n.d. & 5.2 & 1.0 & $10-15$ \\
\hline LTL [0.47, big] & 0.27 & 0.16 & 0.43 & n.d. & 10.1 & 0 & $500-1000$ \\
\hline LTL [0.82] & 0.41 & 0.76 & 1.17 & n.d. & 4.8 & 0.4 & $8-12$ \\
\hline LTL [1.04] & 0.47 & 0.59 & 1.06 & n.d. & 4.9 & 0.7 & $8-12$ \\
\hline LTL [1.53] & 0.18 & 0.78 & 0.97 & n.d. & 5.4 & 0.8 & $15-20$ \\
\hline ASA [2.5] & 0.52 & 0.58 & 1.10 & n.d. & n.d. & n.d. & $8-12$ \\
\hline ASA [11.3] & 0.58 & 0.36 & 0.94 & 1.5 & 4.8 & 0.5 & $8-12$ \\
\hline $\mathrm{SiO}_{2}$ [small] & 0.65 & 0.61 & 1.26 & 1.2 & 6.9 & 0.4 & $30-50$ \\
\hline $\mathrm{SiO}_{2}$ [big] & 0.44 & 0.43 & 0.87 & 1.7 & 7.8 & 0.2 & $60-80$ \\
\hline HT & 0.62 & 0.54 & 1.16 & 1.1 & 5.2 & 0.7 & $10-15$ \\
\hline
\end{tabular}

function of temperature the activation energy for rollover can be determined.

\section{Results}

\subsection{Particle sizes of the reduced catalysts}

In Table 2, the results from HRTEM, $\mathrm{H}_{2}$ chemisorption, the final $\mathrm{Pt}-\mathrm{Pt}$ and $\mathrm{Pt}-\mathrm{O}$ coordination number, and the estimated number of $\mathrm{Pt}$ atoms in the cluster are given. This average number of atoms was estimated with the help of a computer program. This program cuts spheres from a fcc bulk structure and calculates the corresponding Pt-Pt coordination number and dispersion (the ratio of the amount of coordinatively unsaturated $\mathrm{Pt}$ atoms and the total amount of $\mathrm{Pt}$ atoms). A series of spheres with increasing radii was calculated. By comparing the HRTEM, $\mathrm{H}_{2}$ chemisorption, and EXAFS observed particles sizes with the theoretical values of the calculated, spherical clusters, an average number of atoms was estimated.

The Pt/LTL [0.47, small], the other Pt/LTL [*.**] catalysts, both Pt/ASA catalysts, and the Pt/HT all show a high $\mathrm{H} / \mathrm{Pt}$ number with $\mathrm{H}_{\text {total }} / \mathrm{Pt} \geqslant 1.0$ and a Pt-Pt coordination of approximately $N_{\mathrm{PtPt}}=5$. The number of Pt atoms in these particles was estimated at approximately $8-15$ atoms in all cases. For the Pt/ASA [11.3] catalyst, the particle size determined with HRTEM $(1.5 \mathrm{~nm})$ is a little higher than the particle size that is expected based on the $\mathrm{H}_{2}$ chemisorption or $\mathrm{Pt}-\mathrm{Pt}$ coordination number. The $\mathrm{Pt} / \mathrm{SiO}_{2}$ catalysts all showed larger Pt-Pt coordination numbers $\left(N_{\mathrm{PtPt}}=6.9\right.$ and 7.8$)$. The $\mathrm{Pt} / \mathrm{SiO}_{2}$ [small] catalyst, prepared via ion exchange, shows a high $\mathrm{H} / \mathrm{Pt}$ number $\left(\mathrm{H}_{\text {total }} / \mathrm{Pt}=1.26\right)$ in combination with a small particle size as revealed with HRTEM $(1.2 \mathrm{~nm})$. The Pt/LTL [0.47, big] catalyst showed a large particle size, with $\mathrm{H}_{\text {total }} / \mathrm{Pt}=0.43$ and $N_{\mathrm{PtPt}}=10.1$.

\subsection{Particle size effects in $H / D$ exchange}

\subsubsection{Activity as a function of particle size}

The particle-size effect on the activity was measured for two supports, LTL [0.47] and $\mathrm{SiO}_{2}$. The results for these
Table 3

The activity ${ }^{\mathrm{a}}$ and orders for $\mathrm{D}_{2}$ and $\mathrm{CP}$ in $\mathrm{H} / \mathrm{D}$ exchange for the various catalysts

\begin{tabular}{|c|c|c|c|c|c|}
\hline \multirow{2}{*}{$\begin{array}{l}\text { Catalyst, } \\
\mathrm{Pt} /\end{array}$} & \multirow{2}{*}{$\begin{array}{c}\mathrm{TOF} \text { at } 75^{\circ} \mathrm{C} \\
{\left[\mathrm{mol}_{\mathrm{CP}} /\left(\mathrm{mol}_{\mathrm{Pt}} \mathrm{s}\right)\right]}\end{array}$} & \multirow{2}{*}{$\begin{array}{c}E_{\text {app }} \\
(\mathrm{kJ} / \mathrm{mol})\end{array}$} & \multirow[t]{2}{*}{$\ln A_{\text {app }}{ }^{\mathrm{c}}$} & \multicolumn{2}{|c|}{ Order } \\
\hline & & & & $\mathrm{D}_{2}$ & $\mathrm{CP}$ \\
\hline LTL $[0.47$, small $]$ & 4.8 & 73.7 & 27.5 & -0.32 & 0.18 \\
\hline $\operatorname{LTL}[0.47, \mathrm{big}]$ & 10.0 & 66.4 & 25.2 & -0.79 & 0.49 \\
\hline LTL [0.82] & 7.5 & 67.1 & 25.2 & -0.46 & 0.28 \\
\hline $\operatorname{LTL}[1.04]^{\mathrm{b}}$ & 0.2 & n.d. & n.d. & n.d. & n.d. \\
\hline $\operatorname{LTL}[1.53]^{\mathrm{b}}$ & 0.3 & n.d. & n.d. & n.d. & n.d. \\
\hline ASA [2.5] & 7.9 & 56.2 & 21.6 & n.d. & n.d. \\
\hline ASA [11.3] & 10.4 & 56.9 & 22.0 & -0.82 & 0.69 \\
\hline $\mathrm{SiO}_{2}$ [small] & 7.5 & 64.7 & 24.4 & -0.60 & 0.58 \\
\hline $\mathrm{SiO}_{2}[\mathrm{big}]$ & 8.0 & 55.0 & 21.1 & -0.82 & 0.87 \\
\hline $\mathrm{HT}^{\mathrm{b}}$ & $1.6 \times 10^{-3}$ & 66.9 & 16.7 & n.d. & n.d. \\
\hline
\end{tabular}

The TOF is defined as the number of converted $\mathrm{CP}$ atoms per surface $\mathrm{Pt}$ atom per second.

a TOF, $E_{\text {app }}$, and $\ln A_{\text {app }}$ were determined with $P_{\mathrm{D}_{2}}=0.5$ bar, $P_{\mathrm{CP}}=$ 0.025 bar, and $P_{\mathrm{Ar}}=0.475$ bar.

b Due to the low activity, $E_{\text {app }}, E_{\text {app,rollover, }}, \ln A_{\text {app }}$, and the orders in $\mathrm{D}_{2}$ and $\mathrm{CP}$ could not be determined accurately.

${ }^{c}$ Unit of $A_{\mathrm{app}}: \operatorname{mol}_{\mathrm{CP}} /\left(\operatorname{mol}_{\mathrm{Pt}} \mathrm{s}\right)$.

catalysts are given in Table 3 . The TOF (turnover frequency) was of the same order of magnitude, irrespective of the particle size. However, the apparent activation energy is clearly smaller for the larger particles. This lower $E_{\text {app }}$ is compensated by a smaller pre-exponential factor $\ln A_{\text {app }}$.

\subsubsection{Selectivity as a function of particle size}

In Fig. 3, the exchange patterns as measured for the catalysts with the different particle sizes are shown. The selectivity was analyzed using the Monte-Carlo model. The results are given in Table 4.

For both supports it was found that the average number of rotations for each $\pi-\eta^{2}$ intermediate, and, related to this, the desorption probability, is unaffected by the particle size. Also for both supports, larger particles lead to an increased rollover activity via the di $-\sigma-\eta^{1}$ intermediate, whereas the contribution of the di- $\sigma-\eta^{2}$ intermediate is unaffected within the limits of accuracy.

The effect of the particle size on the $\sigma-\eta^{1}$ intermediate (leading to D1) and the total contribution of the $\pi-\eta^{2}$ inter- 


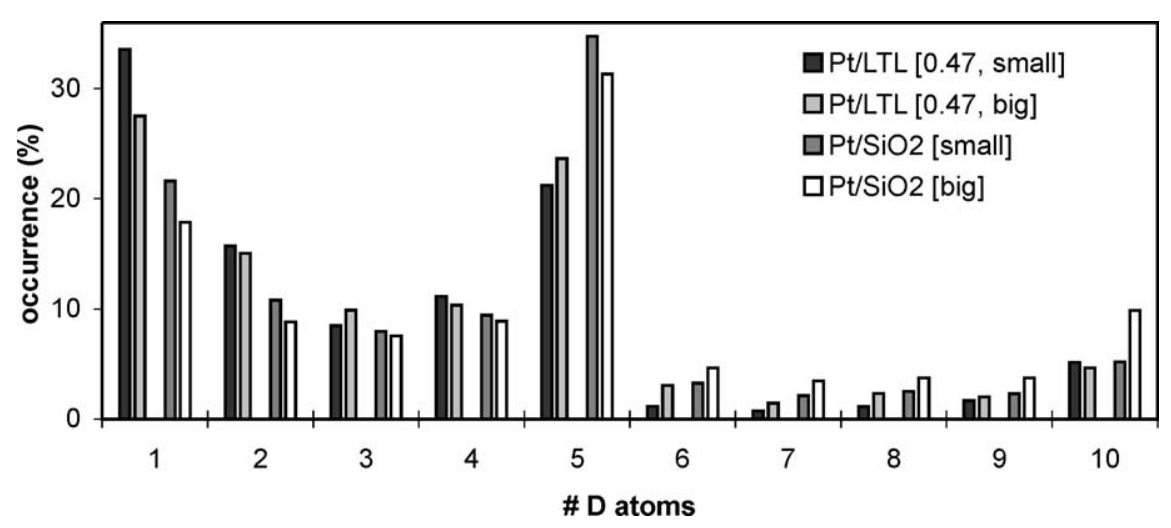

Fig. 3. The influence of the particle size on the exchange pattern. Each first bars represent the Pt/LTL catalysts, the last two bars the Pt/SiO 2 catalysts.

Table 4

The selectivities and activity for the rotation mechanism for the different catalysts, determined at $75^{\circ} \mathrm{C}$, with $P_{\mathrm{D}_{2}}=0.45$ and $P_{\mathrm{CP}}=0.024$ bar

\begin{tabular}{|c|c|c|c|c|c|}
\hline \multirow{2}{*}{$\begin{array}{l}\text { Catalyst, } \\
\mathrm{Pt} /\end{array}$} & \multirow{2}{*}{$\begin{array}{c}\sigma \sigma-\eta^{1} \\
(\mathrm{D} 1) \\
(\%, \pm 1)\end{array}$} & \multirow{2}{*}{$\begin{array}{c}\mathrm{di}-\sigma-\eta^{2} \\
(\mathrm{D} 2) \\
(\%, \pm 1)\end{array}$} & \multicolumn{3}{|c|}{$\pi-\eta^{2}(\mathrm{D} 2-\mathrm{D} 10)$} \\
\hline & & & $\begin{array}{l}\text { Selectivity } \\
(\%, \pm 1)\end{array}$ & $\begin{array}{l}\text { No. rotations } \\
\quad( \pm 0.5)\end{array}$ & $\begin{array}{c}\mathrm{di}-\sigma-\eta^{1} \\
(\mathrm{D} 6-\mathrm{D} 10) \\
(\%, \pm 1)\end{array}$ \\
\hline LTL [0.47, small] & 33.6 & 5.7 & 60.8 & 9.4 & 9.9 \\
\hline LTL $[0.47, \mathrm{big}]$ & 27.5 & 4.2 & 68.3 & 9.0 & 12.6 \\
\hline LTL [0.82] & 30.7 & 4.8 & 64.5 & 8.6 & 12.5 \\
\hline ASA [2.5] & 27.1 & 3.8 & 69.1 & 11.2 & 10.6 \\
\hline ASA [11.3] & 28.1 & 3.7 & 68.3 & 9.5 & 9.5 \\
\hline $\mathrm{SiO}_{2}$ [small] & 21.5 & 3.0 & 75.4 & 13.1 & 15.4 \\
\hline $\mathrm{SiO}_{2}[\mathrm{big}]$ & 17.8 & 2.3 & 79.9 & 12.6 & 25.5 \\
\hline
\end{tabular}

For a description of the different intermediates, see Fig. 1 and Ref. [19].

mediate (D2-D10) is different for the two supports. With the LTL [0.47] support, larger particles do not affect these intermediates. With the $\mathrm{SiO}_{2}$ support, however, larger particles lead to a decrease of the $\sigma-\eta^{1}$ intermediate accompanied by an increase of the $\pi-\eta^{2}$ intermediate.

\subsubsection{Order in $D_{2}$ and $C P$ for activity and selectivity as a function of particle size}

In Table 3, the observed orders in $\mathrm{CP}$ and $\mathrm{D}_{2}$ are given. For both the LTL [0.47] and the $\mathrm{SiO}_{2}$ support, an increase in particle size results in a significant increase of the positive order in $\mathrm{CP}$ and a more negative order in $\mathrm{D}_{2}$.

The experimentally observed influence of the $\mathrm{CP}$ partial pressure on the selectivity as a function of particle size is shown in Fig. 4A. The $\mathrm{Pt} / \mathrm{SiO}_{2}$ [big] catalyst showed no significant changes in the selectivity as a function of the $\mathrm{CP}$ partial pressure. For the other catalysts, $\mathrm{Pt} / \mathrm{SiO}_{2}$ [small] and both Pt/LTL $\left[0.47,{ }^{* *}\right]$ catalysts, an increase in the D1 and $\mathrm{D} 2$ product and a decrease in the $\mathrm{D} 3-\mathrm{D} 5$ products were observed for higher CP partial pressures. The observed selectivities were analyzed with the Monte-Carlo model. The results of this analysis are given in Table 5. Also from this analysis follows that for the $\mathrm{Pt} / \mathrm{SiO}_{2}$ [big] catalyst the contributions of the various intermediates and the average number of rotations do not show a trend with the $\mathrm{CP}$ partial pressure. For the other catalysts, the Monte-Carlo analysis re- veals that, in addition to the above noted changes, both the total contribution of the $\pi-\eta^{2}$ intermediate and the average number of rotations for this intermediate decrease with increasing CP partial pressure.

The influence of the $\mathrm{D}_{2}$ partial pressure is similar for all catalysts as can be seen in Fig. 4B. The Monte-Carlo analysis of this selectivity is given in Table 6. These analyses reveal that increasing the $\mathrm{D}_{2}$ partial pressure resulted in an increased contribution of the $\sigma-\eta^{1}$ intermediate, whereas the amount of the di $-\sigma-\eta^{2}$ intermediate was unaffected. The contribution of the $\pi-\eta^{2}$ and di- $\sigma-\eta^{1}$ intermediates was decreased with increasing $\mathrm{D}_{2}$ partial pressure, but the average number of rotations of the $\pi-\eta^{2}$ intermediate was increased with higher $\mathrm{D}_{2}$ partial pressures.

\subsection{Support effects in $H / D$ exchange}

\subsubsection{Activity as a function of support}

In Table 3 , the turnover frequency $\left(\mathrm{TOF}, \mathrm{mol}_{\mathrm{CP}} /\left(\mathrm{mol}_{\mathrm{Pt}} \mathrm{s}\right)\right)$ and apparent activation energies $(\mathrm{kJ} / \mathrm{mol})$ for the conversion of $\mathrm{CP}$ and the rollover mechanism are given. With the exception of the basic catalysts $(\mathrm{Pt} / \mathrm{LTL}[\mathrm{K} / \mathrm{Al}>1.0]$ and $\mathrm{Pt} / \mathrm{HT}$ ), the TOF at $75^{\circ} \mathrm{C}$ for the different catalysts are all of the same magnitude, approximately $5-10 \mathrm{~mol}_{\mathrm{CP}} /\left(\mathrm{mol}_{\mathrm{Pt}} \mathrm{s}\right)$. The basic catalysts show activities that are up to $10^{4}$ times smaller. The low activity of the basic catalysts prevented the accurate determination of selectivities, activation, energies, and orders in $\mathrm{D}_{2}$ and $\mathrm{CP}$ for these catalysts.

The basic catalysts do not only show a relatively low activity, but in addition they initially produce a large amount of $\mathrm{HD}(\mathrm{g})$ when $\mathrm{CP}$ is added to the gas mixture. When this used catalyst is heated to higher temperature $\left(\sim 450^{\circ} \mathrm{C}\right)$ in $\mathrm{H}_{2}, \mathrm{CH}_{4}$, and $\mathrm{CH}_{3}$ is observed. This indicates the desorption of $\mathrm{CH}_{4}$. These observations are representative for all basic catalysts.

\subsubsection{Selectivity as a function of support}

The experimental selectivity patterns are shown in Fig. 5, the results of the Monte-Carlo analyses are given in Table 4 . Going from acidic to neutral supports, the contribution of the $\pi-\eta^{2}$ intermediate is increased. This is accompanied by 

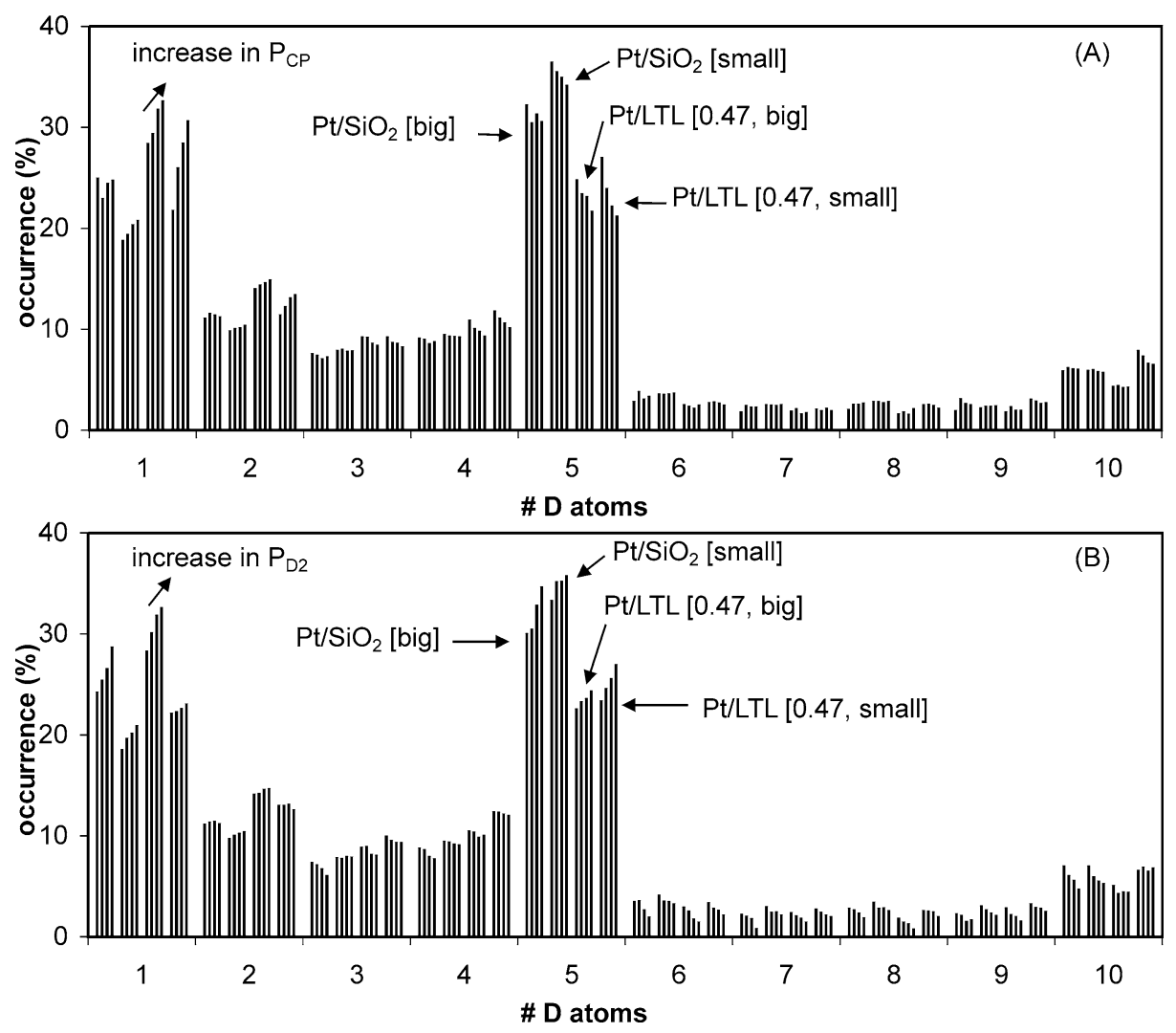

Fig. 4. The influence of the partial pressure of (A) $\mathrm{CP}$ and (B) $\mathrm{D}_{2}$ on the exchange pattern. Four catalysts are shown, $\mathrm{Pt} / \mathrm{SiO}{ }_{2}[\mathrm{big}], \mathrm{Pt} / \mathrm{SiO}{ }_{2}$ [small], $\mathrm{Pt} / \mathrm{LTL}$ [0.47, big], and Pt/LTL [0.47, small]. From left to right for a single product and catalyst represents an increase in partial pressure.

Table 5

The selectivity as a function of partial pressures in $\mathrm{CP}$

\begin{tabular}{|c|c|c|c|c|c|c|c|}
\hline \multirow{2}{*}{$\begin{array}{l}\text { Catalyst, } \\
\mathrm{Pt} /\end{array}$} & \multirow{2}{*}{$\begin{array}{l}P_{\mathrm{CP}} \\
\text { (bar) }\end{array}$} & \multirow{2}{*}{$\begin{array}{l}P_{\mathrm{D}_{2}} \\
\text { (bar) }\end{array}$} & \multirow{2}{*}{$\begin{array}{c}\sigma-\eta^{1} \\
(\mathrm{D} 1) \\
(\%, \pm 1)\end{array}$} & \multirow{2}{*}{$\begin{array}{c}\text { di }-\sigma-\eta^{2} \\
(\mathrm{D} 2) \\
(\%, \pm 1)\end{array}$} & \multicolumn{3}{|c|}{$\pi-\eta^{2}$ (D2-D10) } \\
\hline & & & & & $\begin{array}{c}\text { Total selectivity } \\
(\%, \pm 1)\end{array}$ & $\begin{array}{l}\text { No. rotations } \\
\quad( \pm 0.5)\end{array}$ & $\begin{array}{l}\frac{\operatorname{di}-\sigma-\eta^{1}}{(\mathrm{D} 6-\mathrm{D} 10)}\end{array}$ \\
\hline \multirow[t]{4}{*}{$\mathrm{SiO}_{2}[\mathrm{big}]$} & 0.015 & 0.44 & 25.0 & 3.3 & 71.7 & 12.9 & 14.8 \\
\hline & 0.021 & & 23.0 & 3.7 & 73.3 & 12.5 & 18.4 \\
\hline & 0.029 & & 24.5 & 3.7 & 71.8 & 13.2 & 16.9 \\
\hline & 0.036 & & 24.8 & 3.6 & 71.6 & 12.7 & 17.2 \\
\hline \multirow[t]{4}{*}{$\mathrm{SiO}_{2}$ [small] } & 0.016 & 0.46 & 18.8 & 2.6 & 78.7 & 13.6 & 17.3 \\
\hline & 0.021 & & 19.4 & 2.6 & 78.0 & 13.2 & 17.5 \\
\hline & 0.027 & & 20.4 & 2.9 & 76.7 & 13.2 & 17.2 \\
\hline & 0.033 & & 20.9 & 2.9 & 76.2 & 13.0 & 17.4 \\
\hline \multirow[t]{4}{*}{ LTL $[0.47, \mathrm{big}]$} & 0.017 & 0.46 & 28.4 & 4.2 & 67.4 & 9.7 & 12.4 \\
\hline & 0.022 & & 29.4 & 4.3 & 66.3 & 9.2 & 13.3 \\
\hline & 0.027 & & 31.9 & 4.7 & 63.4 & 9.6 & 11.8 \\
\hline & 0.032 & & 32.7 & 4.7 & 62.6 & 9.4 & 12.8 \\
\hline \multirow[t]{4}{*}{ LTL $[0.47$, small] } & 0.014 & 0.45 & 21.8 & 3.2 & 75.1 & 10.2 & 18.5 \\
\hline & 0.026 & & 26.1 & 3.7 & 70.2 & 9.9 & 17.8 \\
\hline & 0.037 & & 28.5 & 4.2 & 67.2 & 9.4 & 16.8 \\
\hline & 0.048 & & 30.7 & 4.6 & 64.7 & 9.3 & 16.1 \\
\hline
\end{tabular}

a decrease in the production of the D1 product via the $\sigma-\eta^{1}$ intermediate and by a decrease in the amount of D2 product formed via the di $-\sigma-\eta^{2}$ intermediate. Within the zeolites, the total number of exchange steps each $\pi$-bonded intermediate undergoes is considerably less than on the mesoporous supports.

\subsubsection{Orders in $\mathrm{CP}$ and $\mathrm{D}_{2}$ as a function of support}

The observed orders in $\mathrm{D}_{2}$ and $\mathrm{CP}$ are given in Table 3. The order in $\mathrm{D}_{2}$ increases from -0.82 for the $\mathrm{H} / \mathrm{D}$ exchange over Pt/ASA [11.3] to -0.32 over Pt/LTL [0.47, small]. The latter catalyst contains the most acidic support. The increase in the order in $\mathrm{D}_{2}$ is accompanied by a decrease in the or- 
Table 6

The selectivity as a function of partial pressures of $\mathrm{D}_{2}$

\begin{tabular}{|c|c|c|c|c|c|c|c|}
\hline \multirow{2}{*}{$\begin{array}{l}\text { Catalyst } \\
\mathrm{Pt} /\end{array}$} & \multirow[t]{2}{*}{$P_{\mathrm{CP}}($ bar $)$} & \multirow[t]{2}{*}{$P_{\mathrm{D}_{2}}$ (bar) } & \multirow{2}{*}{$\begin{array}{c}\sigma-\eta^{1}(\mathrm{D} 1) \\
(\%, \pm 1)\end{array}$} & \multirow{2}{*}{$\begin{array}{c}\mathrm{di}-\sigma-\eta^{2}(\mathrm{D} 2) \\
(\%, \pm 1)\end{array}$} & \multicolumn{3}{|c|}{$\pi-\eta^{2}(\mathrm{D} 2-\mathrm{D} 10)$} \\
\hline & & & & & Selectivity $(\%, \pm 1)$ & No. rotations $( \pm 0.5)$ & $\operatorname{di}-\sigma-\eta^{1}(\mathrm{D} 6-\mathrm{D} 10)(\%, \pm 1)$ \\
\hline \multirow[t]{4}{*}{$\mathrm{SiO}_{2}[\mathrm{big}]$} & 0.023 & 0.34 & 24.3 & 3.4 & 72.4 & 12.5 & 18.1 \\
\hline & & 0.43 & 25.4 & 3.6 & 70.9 & 12.9 & 16.7 \\
\hline & & 0.52 & 26.6 & 3.7 & 69.7 & 14.2 & 14.2 \\
\hline & & 0.62 & 28.8 & 3.8 & 7.3 & 15.9 & 11.3 \\
\hline \multirow[t]{4}{*}{$\mathrm{SiO}_{2}[$ small $]$} & 0.024 & 0.33 & 18.6 & 2.5 & 78.8 & 12.9 & 20.8 \\
\hline & & 0.42 & 19.8 & 2.8 & 77.4 & 13.4 & 17.7 \\
\hline & & 0.51 & 20.2 & 2.7 & 77.1 & 13.2 & 17.0 \\
\hline & & 0.55 & 21.0 & 2.9 & 76.0 & 13.3 & 16.6 \\
\hline \multirow[t]{4}{*}{ LTL $[0.47$, big $]$} & 0.024 & 0.35 & 28.3 & 4.3 & 67.4 & 9.4 & 15.4 \\
\hline & & 0.41 & 30.3 & 4.6 & 65.2 & 9.4 & 12.8 \\
\hline & & 0.49 & 32.0 & 4.7 & 63.3 & 10.2 & 11.6 \\
\hline & & 0.55 & 32.7 & 5.3 & 62.0 & 10.3 & 9.9 \\
\hline \multirow[t]{4}{*}{ LTL $[0.47$, small $]$} & 0.022 & 0.32 & 22.2 & 3.9 & 73.9 & 8.9 & 18.8 \\
\hline & & 0.43 & 22.4 & 3.9 & 73.7 & 9.5 & 17.9 \\
\hline & & 0.54 & 22.7 & 4.2 & 73.1 & 9.8 & 16.9 \\
\hline & & 0.65 & 23.1 & 3.8 & 73.0 & 10.2 & 15.7 \\
\hline
\end{tabular}

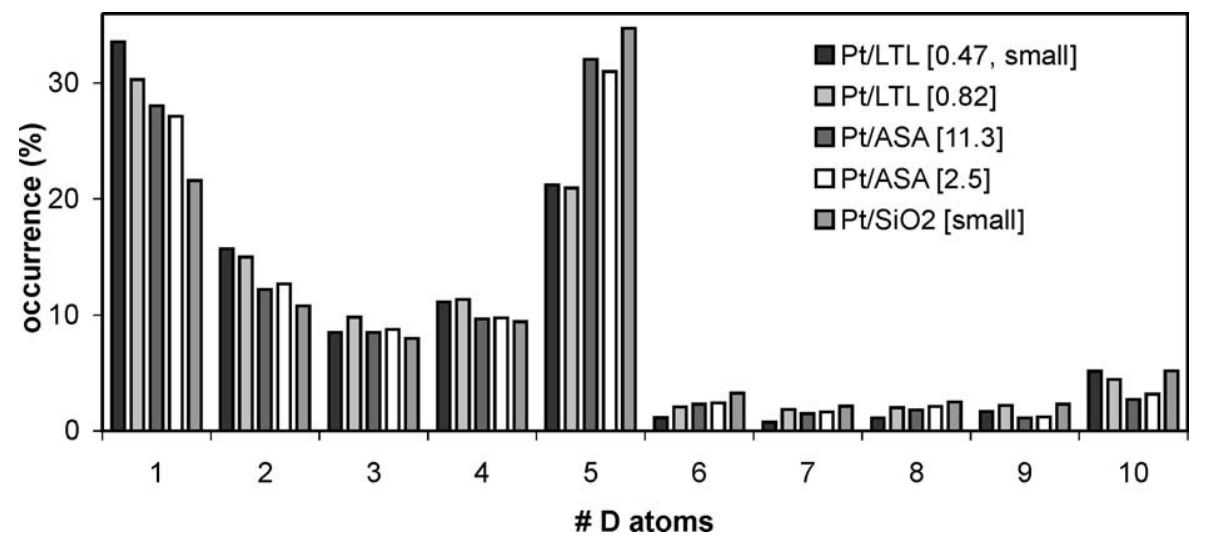

Fig. 5. The influence of the support in the exchange pattern.

der in CP from 0.69 (Pt/ASA [11.3]) to only 0.18 (Pt/LTL [0.47, small]). In Fig. 4A, it is shown that increasing the CP partial pressure over catalyst Pt/LTL [0.47, small] results in large changes in the selectivity. In contrast, the catalyst with the highest order in $\mathrm{CP}\left(+0.87\right.$, catalyst $\mathrm{Pt} / \mathrm{SiO}_{2}$ [big] $)$ shows no effect of the $\mathrm{CP}$ partial pressure on the selectivity.

\section{Discussion}

\subsection{The acidity of the support materials}

On order to understand the effect of support acidity, it is important to clearly understand the acidities of the support that are used in this study.

The number of acid sites of the two amorphous, mesoporous $\mathrm{SiO}_{2}-\mathrm{Al}_{2} \mathrm{O}_{3}$ (ASA) supports was determined with the combination of thermographic analysis and temperatureprogrammed desorption of isopropylammine [28]. The number of Brønsted acid sites was 1.20 (ASA [2.5]) and $0.28 \mathrm{mmol} / \mathrm{g}$ (ASA [11.3]). Based upon the $\mathrm{Si} / \mathrm{Al}$ ratio, this means that only about $20 \%$ results in acid sites. Only Al atoms incorporated into the tetrahedral $\mathrm{SiO}_{2}$ framework will result in acid sites. The low number of acid sites makes it unlikely that two acid sites influence each other, and the acid sites are locally (within the distance of a few atoms) similar for both ASA supports. The main difference between those two ASA support materials is the number of acid sites, not the intrinsic acidity of the site.

The LTL zeolites have a Si/Al ratio of 3.0 [29]. Based upon the crystallographic formula of LTL $\left(\left[\mathrm{K}_{9}\left(\mathrm{H}_{2} \mathrm{O}\right)_{21}\right]\right.$ $\left[\mathrm{Al}_{9} \mathrm{Si}_{27} \mathrm{O}_{72}\right]$ ), the number of Brønsted acid sites in the LTL with a $\mathrm{K} / \mathrm{Al}=0.47$ is $1.76 \mathrm{mmol} / \mathrm{g}$. In the case of the LTL [0.82], this is $0.57 \mathrm{mmol} / \mathrm{g}$. The LTL zeolites with $\mathrm{K} / \mathrm{Al}>1$ have no Brønsted acid sites, and after calcination at elevated temperatures, the excess $\mathrm{K}$ is probably present as $\mathrm{KOH}$ or $\mathrm{K}_{2} \mathrm{O}$. Increased amounts of $\mathrm{K}$ result in a more basic support, with an increased electron richness on the support oxygen atoms [30-32].

The number of Brønsted acidic sites is similar for the ASA and LTL $[\mathrm{K} / \mathrm{Al}<1.0]$ supports. However, the Pt parti- 
cles are influenced rather by the electron richness of the support oxygen than by the number of Brønsted acid sites [12], as has been shown earlier $[9,10]$. In the covalent zeolite framework, the electron richness on the oxygen atom is much lower than on a support like ASA [31,33,34]. In that sense, a zeolite is much more acidic.

$\mathrm{SiO}_{2}$ is a neutral material, and has no acid sites. The $\mathrm{SiO}_{2}$ used was highly amorphous and contains a high surface area.

A hydrotalcite is regarded as a very basic support. It consists of platelets in a brucite structure, with $\mathrm{Mg}^{2+}$ ions octahedrally coordinated by $\mathrm{O}$ atoms. Part of the $\mathrm{Mg}^{2+}$ ions are isomorphically exchanged for $\mathrm{Al}^{3+}$ ions, creating a positive charge on the framework. Between the platelets, this positive charge is compensated with $\mathrm{CO}_{3}{ }^{-}$or $\mathrm{OH}^{-}$ions. The $\mathrm{OH}^{-}$ ions located at the edge of the platelets are active in basic catalysis. Also Pt particles are located at the edges of the platelets, near the $\mathrm{OH}^{-}$ions, and they experience the support material as basic.

When all the noted support materials are compared, and if the electron richness of the support oxygen atoms is taken as a measure of acidity, then the acidity for the applied support materials increases in the order HT $<$ LTL $[1.53]<$ LTL $[1.04]<\mathrm{SiO}_{2}<$ ASA [11.4] $=$ ASA [2.5] $<$ LTL [0.82] $<$ LTL [0.47].

\subsection{Final metal particle sizes}

For the $\mathrm{SiO}_{2}$ support material, two different particle sizes were obtained. All techniques used reveal a smaller final metal particle size for the ion-exchanged catalysts compared to the impregnated catalyst. This is probably caused by a better anchoring of the $\mathrm{Pt}^{2+}$ complex during ion exchange than during impregnation. HRTEM, $\mathrm{H}_{2}$ chemisorption, and EXAFS showed somewhat contradictory results for the ionexchanged catalyst (Table 2). The high $\mathrm{H}_{\text {total }} / \mathrm{Pt}$ ratio of 1.26 is in contrast with the diameter $(1.2 \mathrm{~nm})$ as revealed by HRTEM and Pt-Pt coordination number of 6.9. The latter two are in perfect agreement; based upon spherical particles with a diameter of $1.2 \mathrm{~nm}$ an average coordination number of 7.0 would be expected (see, e.g., Ref. [35]). The origin of the discrepancy with $\mathrm{H}_{2}$ chemisorption is unclear.

The particle sizes for both $\mathrm{Pt} / \mathrm{SiO}_{2}$ catalysts are higher than for the other catalysts. The larger particle size for the $\mathrm{Pt} / \mathrm{SiO}_{2}$ catalysts illustrates that it is very difficult to achieve highly dispersed metal particles on an inert support material. When no interaction between the support and the metal particles is present, the support material loses its primary function: to keep the metal particles highly dispersed.

The Pt/LTL [*.**], Pt/LTL [0.47, small], Pt/ASA and $\mathrm{Pt} / \mathrm{HT}$ catalysts all have highly dispersed Pt particles. Based on the $\mathrm{H}_{\text {total }} / \mathrm{Pt}$ and $N_{\mathrm{PtPt}}$ results, the average particle size for all these catalysts was estimated at $<1 \mathrm{~nm}$. The particle size for the Pt/ASA catalyst as revealed with HRTEM $(1.5 \mathrm{~nm})$ seems in contradiction with the other techniques. However, it must to be noted that with HRTEM the lower detection limit for Pt/ASA is approximately 8-10 $\AA$, and that on the HRTEM pictures taken only a small amount of particles was visible. In other words, with HRTEM the smallest particles, which make up the majority of all $\mathrm{Pt}$ in the Pt/ASA catalyst, are invisible. The relation between particle sizes as determined with HRTEM, $\mathrm{H}_{2}$ chemisorption, and EXAFS was extensively described by de Graaf et al. [35].

\subsection{Particle-size effects}

\subsubsection{Activity as a function of metal particle size}

For larger supported metal particles, the apparent activation energy for the $\mathrm{H} / \mathrm{D}$ exchange is significantly higher (Table 3). This is observed with both support materials $\left(\mathrm{SiO}_{2}\right.$ and LTL [0.47]). However, with both support materials, the TOF at $75^{\circ} \mathrm{C}$ is of the same magnitude, irrespective of particle size. At first sight, this seems contraintuitive as the apparent activation energy is approximately $15-20 \%$ higher for the smaller particles. However, as can be seen in Table 3, this increase in activation energy was compensated for by an increase in the pre-exponential factor. This suggests that a compensation effect is present, as will be discussed later $[23,24]$.

\subsubsection{Selectivity as a function of metal particle size}

Fig. 3 (experiments) and Table 4 (results of Monte-Carlo analysis) give the selectivities in the $\mathrm{H} / \mathrm{D}$ exchange of $\mathrm{CP}$ with the same two support materials. On the $\mathrm{SiO}_{2}$ support, the presence of larger particles leads to slightly decreased amounts of the $\sigma-\eta^{1}$ intermediate, the di- $\sigma-\eta^{2}$ intermediate is unaffected, whereas the total contribution of the $\pi-\eta^{2}$ intermediate is slightly increased. In contrast to the latter, the average number of rotations of the $\pi-\eta^{2}$ intermediate is insensitive to the particle size of the catalyst. Apparently, the formation of the $\pi-\eta^{2}$ intermediate is structure sensitive, but once the $\pi-\eta^{2}$ is formed it can rotate freely. On the LTL [0.47] support, larger particles do not affect the relative contributions of the $\sigma-\eta^{1}$, di $-\sigma-\eta^{2}$, and $\pi-\eta^{2}$ intermediates. Overall, the influence of the particle size on these relative contributions is minimal for both supports.

The particle-size effect is for both supports the largest for the selectivity toward the rollover mechanism (via the di- $\sigma$ $\eta^{1}$ intermediate, Fig. 1D), which is strongly increased with the larger particles. Hence, also the rollover mechanism is a clearly structure-sensitive reaction. It is facilitated by large particles, and probably an ensemble of catalytically active, empty sites is needed for the formation of the di $-\sigma-\eta^{1}$ intermediate.

If the $\mathrm{Pt} / \mathrm{SiO}_{2}$ [big] is compared with LTL [0.47, big], then the particles are the largest on the LTL [0.47] support, but the rollover mechanism is much more important on the $\mathrm{Pt} / \mathrm{SiO}_{2}$ support. Probably, the freedom of the $\mathrm{CP}$ is limited within the constraints of the pores in the LTL zeolite and rolling over is sterically hindered. 


\subsubsection{Orders in $C P$ and $D_{2}$ as a function of metal particle} size

The orders in $\mathrm{CP}$ and $\mathrm{D}_{2}$ for $\mathrm{H} / \mathrm{D}$ exchange over the $\mathrm{Pt} / \mathrm{LTL}\left[0.47\right.$ ] and $\mathrm{Pt} / \mathrm{SiO}_{2}$ [ $^{* *}$ ] catalysts are given in Table 3. For both supports, the order in $\mathrm{D}_{2}$ decreased (it was more negative) and the order in CP increased when a catalyst with a larger particle size was used. When these observations are correlated to Eq. (2) for the reaction rate, the lower order in $\mathrm{D}_{2}$ indicates that for larger particles the ratio $K_{2} / K_{1}$ is increased for larger particles. In other words, for larger particles the surface of the Pt particles is mainly covered with (atomic) $\mathrm{D}_{2}$, whereas for smaller particles, the surface contains more adsorbed CP. Although the particles were largest in the case of the Pt/LTL [0.47, big] catalyst, the order in $\mathrm{CP}$ was the highest for the $\mathrm{Pt} / \mathrm{SiO}_{2}$ [big] catalyst. Clearly, the orders also depend on the support material.

In general, a high order in CP (e.g., +0.87 , as was found in the case of the $\mathrm{Pt} / \mathrm{SiO}_{2}$ [big] catalyst) indicates that the surface contains on average a very low concentration of $\mathrm{CP}$ : by doubling the amount of CP molecules in the gas phase, the surface concentration is doubled. This can only occur if during the adsorption process the $\mathrm{CP}$ molecule does not encounter another $\mathrm{CP}$ molecule which is already adsorbed. The surface is virtually covered with atomic D (indicated by the order in $\mathrm{D}_{2}$ of -0.82 for $\mathrm{Pt} / \mathrm{SiO}_{2}$ [big]), and the surface concentration of $\mathrm{D}$ is unaffected by the $\mathrm{CP}$ partial pressure. The low surface concentration of $\mathrm{CP}$ also explains the observation that the exchange pattern of $\mathrm{CP}$ is unaffected by $\mathrm{P}_{\mathrm{CP}}$ for this $\mathrm{Pt} / \mathrm{SiO}_{2}$ [big] catalyst: the surface contains only a small amount of $\mathrm{CP}$ and adsorbed CP molecules do not influence each other due to mutual (lateral) interactions.

However, decreased orders in CP and increased (less negative) orders in $\mathrm{D}_{2}$ are found for smaller particles (e.g., when $\mathrm{Pt} / \mathrm{SiO}_{2}$ [big] and $\mathrm{Pt} / \mathrm{SiO}_{2}$ [small] or both Pt/LTL [0.47] catalysts are compared). When these orders are translated to the rate expression Eq. (2), it indicates that the ratio $K_{2} / K_{1}$ is decreased, and the surface contains more CP. A high surface coverage of $\mathrm{CP}$ can result in lateral interactions which influences the selectivity pattern. These lateral interactions can consist of long-range electronic interactions or of steric interactions between two adjacent, adsorbed CP molecules. Therefore, it is to be expected that a relatively low order in $\mathrm{CP}$ is accompanied by an increased amount of lateral interactions by increasing the $\mathrm{CP}$ partial pressure, which inhibit mainly the structure sensitive reactions (rollover via the di$\sigma-\eta^{1}$ intermediate). This is indeed observed in Fig. 4A and Table 5 .

\subsection{Support effects}

\subsubsection{Activity as a function of support}

As is shown in Table 3 , the TOF at $75^{\circ} \mathrm{C}$ is several orders of in magnitude lower for the basic Pt/LTL [1.53] and $\mathrm{Pt} / \mathrm{HT}$ catalysts compared to the acidic and neutral catalysts. In addition, the basic catalysts showed a consumption of $D_{2}$ in the initial stages of the $H / D$ exchange without a production of CP. Moreover, a desorption of $\mathrm{CH}_{4}$ was observed when these basic catalysts were heated in $\mathrm{H}_{2}$ to high temperatures. These observations suggest an immediate deactivation of the basic catalysts due to coking. This indicates that the $\mathrm{CP}$ molecule is strongly bonded on the Pt particles supported by a basic material, and it does not desorb anymore.

The activation energies for the remaining acidic and neutral catalysts show a continuous decline for the apparent activation energies in the order Pt/LTL [0.47, small] $>\mathrm{Pt} / \mathrm{LTL}$ $[0.47, \mathrm{big}]>\mathrm{Pt} / \mathrm{LTL}[0.82]>\mathrm{Pt} / \mathrm{ASA} \approx \mathrm{Pt} / \mathrm{SiO}_{2}[\mathrm{small}] \approx$ $\mathrm{Pt} / \mathrm{SiO}_{2}$ [big]. The pre-exponential factor increases in the opposite direction. These observations indicate an apparent compensation effect, as will be discussed later.

\subsubsection{Selectivity as a function of support}

As is shown in Fig. 5 (experiments) and Table 4 (MonteCarlo analysis), a general trend is that Pt catalysts with supports of higher acidity lead to a higher contribution of the $\sigma-\eta^{1}$ (D1) and di $-\sigma-\eta^{2}$ (D2) intermediates. As the ASA and LTL supports have similar metal particle sizes, this cannot be explained by particle-size effects. Apparently, acidic supports enhance the ability of Pt to form $\sigma$-bonded species, whereas $\pi$ bonded species are preferred for Pt on neutral, and probably also on basic, support materials. The latter is not only apparent from the increased selectivity toward D2D10, but also from an increased number of exchange steps (or rotations) the $\pi-\eta^{2}$ intermediate experiences. This increased number of exchange steps indicates that both the $\pi-\eta^{2}$ and the allylic intermediates adsorb strongly on the surface of Pt particles that are supported on neutral supports, and remain longer on this surface.

\subsubsection{Orders in $C P$ and $D_{2}$ as a function of support}

As is shown in Table 3, the order in CP decreases from +0.87 to +0.18 going from Pt particles with neutral to acidic supports. This is accompanied by an increase in the order in $\mathrm{D}_{2}$ from -0.82 to -0.32 . In general, a low, positive order in a reactant indicates that the surface concentration of the reactant on the catalytic surface is relatively high. The low order in $\mathrm{CP}$, in combination with the decreased inhibition by $\mathrm{D}_{2}$ for $\mathrm{H} / \mathrm{D}$ exchange of $\mathrm{CP}$ over Pt with the most acidic support (catalyst Pt/LTL [0.47, small]), shows that-compared to a Pt catalyst with a neutral support - the surface contains a relatively high concentration of $\mathrm{CP}$ and low concentration of D.

The surface concentrations are related to the bond energy of D and CP on the Pt surface, and apparently the ratio $E_{\mathrm{CP}-\mathrm{Pt}} / E_{\mathrm{D}-\mathrm{Pt}}$ is higher for Pt on the acidic support materials than it is for the neutral supports. It was shown earlier [19] (see also Table 6) that the rotation of the $\pi-\eta^{2}$ intermediate is facilitated by an increased surface coverage of D. Also, in agreement with this, the catalysts $\left(\mathrm{Pt} / \mathrm{SiO}_{2}\left[{ }^{* *}\right]\right)$ which have the lowest $\mathrm{E}_{\mathrm{CP}-\mathrm{Pt}} / \mathrm{E}_{\mathrm{D}-\mathrm{Pt}}$ ratio and thus the highest surface coverage of $\mathrm{D}$ also have the highest number of average rotations per $\pi-\eta^{2}$ intermediate (Table 4 ). 


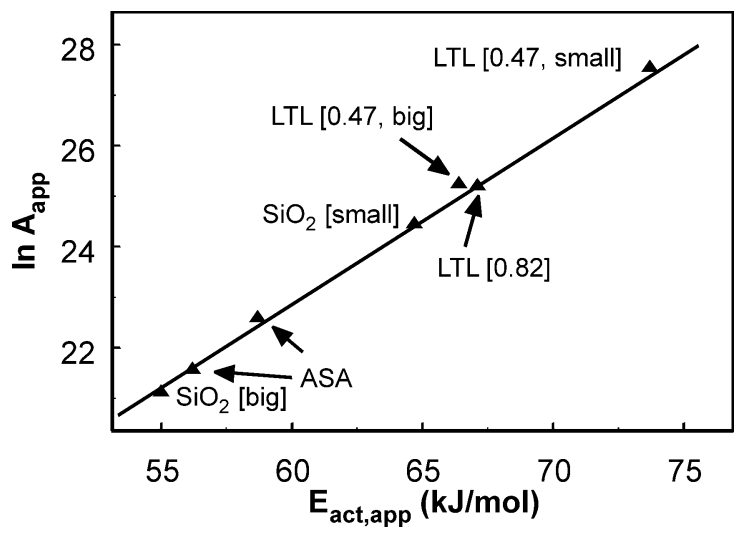

Fig. 6. A constable plot for the HD exchange. The estimated errors are approximately $\pm 2 \mathrm{~kJ} / \mathrm{mol}$ for $E_{\text {act, app }}$ and \pm 0.5 for $\ln A_{\text {app }}$.

\subsection{Compensation phenomena}

When the Arrhenius parameters $E_{\text {app }}$ and $\ln A_{\text {app }}$ of a variety of catalysts obey the Constable-Cremer isokinetic relation $[23,24,36]$,

$\ln A_{\text {app }}=m E_{\text {app }}+c$,

then an increase in $E_{\text {app }}$ is compensated by an increase in $\ln A_{\text {app }}$. This is called the compensation effect. In Fig. 6, a Constable plot for all catalysts is shown. The observation that all Arrhenius parameters for all catalysts obey the Constable-Cremer relation indeed suggests that compensation behavior is present. According to the standards set by Bond et al. [23] the range in $E_{\text {app }}$ should ideally be at least $50 \%$ of the smallest $E_{\text {app }}$ measure, which is close to our $35 \%$.

If $E_{\text {app }}$ and $\ln A_{\text {app }}$ indeed obey to the Constable-Cremer relation, then there must be an isokinetic relation between all catalysts. At the isokinetic temperature, the activities for all catalysts are the same. However, it is very difficult to establish this isokinetic relation with statistical certainty. Therefore, a second, more reliable way to establish the presence of an isokinetic behavior is to plot all activity plots in one graph, and to check if there is an isokinetic temperature $T_{\mathrm{i}}$ where all activity plots intersect. Since the parameters in such a plot (1/ $T$ and $\ln$ TOF) are measured independently, it is statistically more reliable than a Constable plot. Such a plot is constructed in Fig. 7. All Arrhenius plots for the different catalysts appear to intersect, approximately around $T_{\mathrm{i}}=90-100^{\circ} \mathrm{C}$.

Both the Constable plot (Fig. 6) and the intersecting Arrhenius plots (Fig. 7) strongly suggests that indeed an isokinetic relation (IKR) between $A_{\text {app }}$ and $E_{\text {app }}$ exists. The errors in the determination of these Arrhenius plots and its derived variables prevent the establishment of this IKR with absolute certainty. According to Bond et al. [23], an IKR is most likely caused by changes in the surface coverage of the reactants, and the true activation energy is unaffected. The relation of the chemisorption of reactants (and inhibitors) with the activation energy and reaction rate is basically given

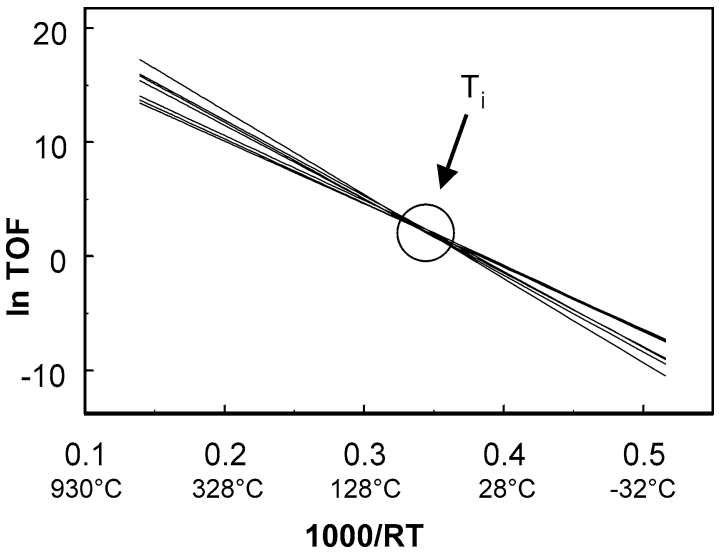

Fig. 7. A series of extrapolated Arrhenius plots for the HD exchange of cyclopentane, intersecting at $T_{\mathrm{i}}$ : the isokinetic temperature.

by the Temkin equation $[23,37]$,

$R=A_{\text {app }} \mathrm{e}^{-\Delta E_{\text {app }} / R T}$,

where

$E_{\text {app }}=\Delta H_{\text {intrinsic }}^{ \pm}+\alpha \Delta H_{\text {ads }, \mathrm{D}}+\beta \Delta H_{\text {ads }, \mathrm{CP}}$,

and

$A_{\text {app }}=P_{\mathrm{D}_{2}}^{\alpha} P_{\mathrm{CP}}^{\beta} \mathrm{e}^{\left(\Delta S_{\text {int }}^{\mp}+\alpha \Delta S_{\text {ads }, \mathrm{D}}+\beta \Delta S_{\text {ads }, \mathrm{CP}}\right) / R}$

where $R$ the reaction rate per Pt surface site (TOF); $k_{\text {int }}$, the intrinsic rate constant of the reaction over the catalyst; $\alpha$, the observed order in deuterium, which was negative in all cases; and $\beta$, the observed order in $\mathrm{CP}$, which is positive.

Thus, changes in the pre-exponential factor $A_{\text {app }}$ represent mainly changes in the adsorption entropy and in the order of the reactants, and changes in $E_{\text {app }}$ reflect changes in the adsorption enthalpy and the order of the reactants. The observed obedience to the linearity of Constable-Cremer relation [Eq. (3)] indicates that $\Delta S$ and $\Delta H$ are correlated. In other words, stronger adsorbed species have a higher adsorption enthalpy, but they also have less degrees of freedom and thus a lower entropy. The phenomenon that $\Delta S$ and $\Delta H$ are linearly correlated is known as "Linear Free-Energy Relations," (LFER) [38].

The adsorption enthalpy has a large influence on the reaction order, as can be seen in Eq. (5): if the adsorption energy of a reactant is high, the surface coverage will be high and nearly independent of temperature or pressure, which leads to a low order of this reactant.

Thus, it is very likely that different chemisorption strengths of the reactants on the catalyst's surface are the origin of the observed isokinetic relationship. In the previous paper [19], it was shown that the activity and selectivity are independent of each other: the selectivity is only determined after the rate-determining step. The rate-determining step is the dissociation of molecularly adsorbed $\mathrm{CP}$ into $\left.\mathrm{H}^{*}\right)$ and $\mathrm{C}_{5} \mathrm{H}_{9}\left({ }^{*}\right)$, leading to the $\sigma-\eta^{1}$ intermediate, and the following steps include the formation of the other possible intermediates like $\pi-\eta^{2}$ (see the energy scheme in Fig. 8). This means 


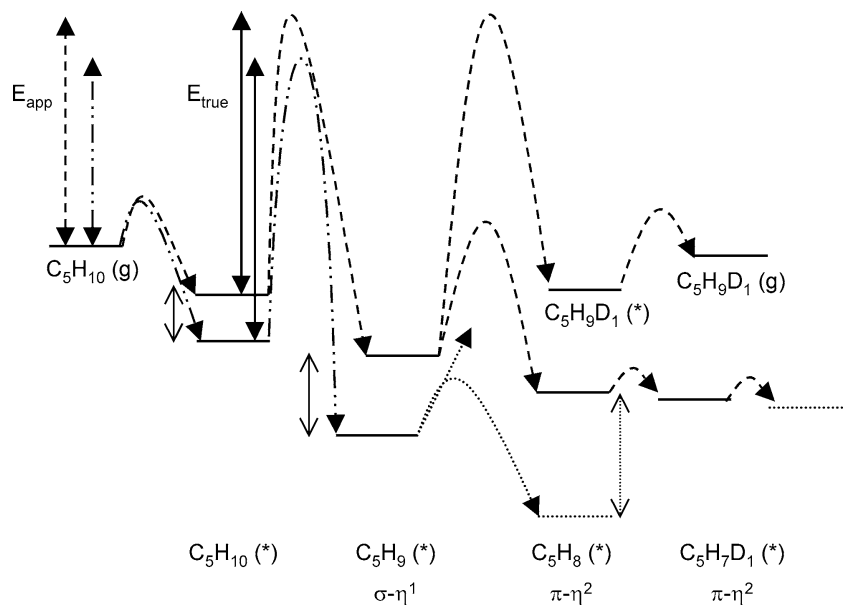

Fig. 8. The energy scheme for the H/D exchange of CP. The apparent activation energy $E_{\text {app }}$ is influenced by the bonding properties of $\mathrm{CP}$. If $\mathrm{CP}$ is bonded strongly on the Pt surface (represented by the dashed-dotted lines), the $E_{\text {app }}$ is small even though the true activation energy is unaffected.

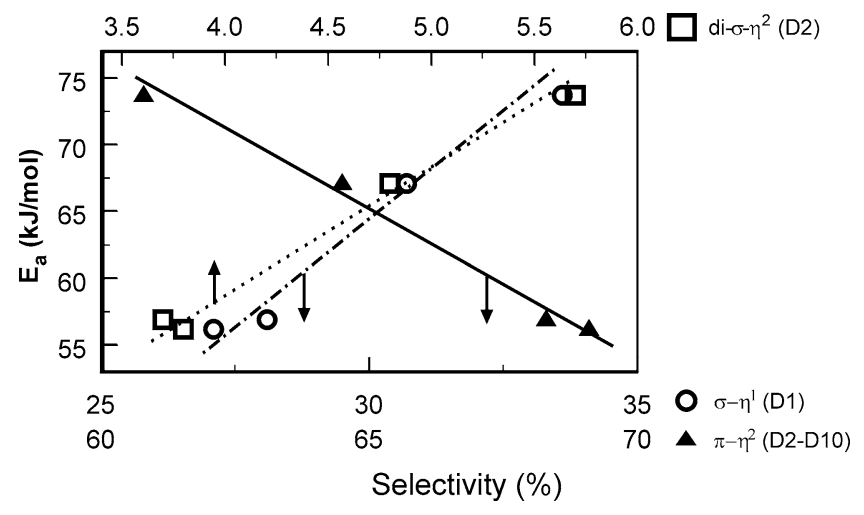

Fig. 9. The relation between $E_{\text {app }}$ and the exchange via the $\sigma-\eta^{1}$ intermediate (leading to D1, circles and dashed-dotted line), the di- $\sigma-\eta^{2}$ intermediate (D2, triangles and dotted line), and the $\pi-\eta^{2}$ intermediate (D2-D10, squares and solid line).

that the compensation effect is only correlated to the adsorption strength of molecularly adsorbed intermediate and the $\sigma-\eta^{1}$ intermediate, and not necessarily to the adsorption energies of all adsorbed intermediates. However, in the case of catalyst with similar particle sizes in combination with different supports, it is likely that if one adsorption mode is influenced by the acidity of the support, the other adsorption modes also are influenced in a similar manner by the support and that some trend between selectivity and $E_{\text {app }}$ should exist. If the particle sizes vary, other effects like the number of available ensembles of sites may start to play a role in the selectivity.

In Fig. 9, the relation between the contribution of the different exchange mechanisms and the apparent activation energy for H/D exchange of CP over four catalysts with various acidities but similar particle sizes is shown. By choosing these four catalysts, particle-size effects are eliminated. There is a clear correlation visible: a higher $E_{\text {app }}$ is accompanied by a higher contribution of the exchange via the $\sigma-\eta^{1}$ and the di- $\sigma-\eta^{2}$ intermediate, and a lower contribution of the $\pi-\eta^{2}$ intermediate. Remarkably, even though no relation between the activity and selectivity was observed, there is a clear correlation between $E_{\text {app }}$ and the selectivity. This clearly illustrates that the metal-support interaction has a dramatic influence on the Pt particles and on the chemisorption of reactants on this Pt. Chemisorption of reactants on the $\mathrm{Pt}$ surface involves the donation and sharing of electrons between the Pt particles and the reactants. Therefore, changes in the chemisorption must be caused by changes in the electronic properties of either the Pt particles or the reactants. Since the reactants are always the same molecules, the changes in the chemisorption strengths must be caused by changes in the electronic properties of the supported Pt particles. This is discussed in more detail in an other paper [39].

\section{Conclusions}

The influence of the support on the catalytic properties of supported $\mathrm{Pt}$ particles was investigated via a test reaction: the H/D exchange of cyclopentane. The acidity of the support largely influences the activity and selectivity of supported Pt particles in the H/D exchange of cyclopentane. The activities for the different catalysts show an isokinetic relation (IKR): the Arrhenius parameters $A_{\text {app }}$ and $E_{\text {app }}$ show a compensation, and at the isokinetic temperature of $\sim 100^{\circ} \mathrm{C}$ all catalysts show similar activities. This IKR is caused by variations in the adsorption strengths of the reactants $\mathrm{CP}$ and $\mathrm{D}_{2}$ on the $\mathrm{Pt}$ surface. The resulting ratios of the surface coverages $\mathrm{CP}\left({ }^{*}\right) / \mathrm{D}\left(^{*}\right)$ are high for acidic supports and low for neutral and basic supports, as is apparent from the observed reaction orders. The variations in the chemisorption strengths of $\mathrm{CP}$ on the Pt are also apparent from changes in selectivity. On Pt with acidic supports, the formation of the $\sigma$-bonded $\eta^{1}$-cyclopentyl intermediate is favored, whereas with neutral and basic supports the formation of a $\pi$-bonded $\eta^{2}$-cyclopentene intermediate is preferred. When particle-size effects are eliminated, the apparent activation energy $E_{\text {app }}$ directly correlates with the selectivity. This is caused by support-acidity induced differences in the electronic properties of the Pt.

\section{References}

[1] G. Blyholder, J. Mol. Catal. A 119 (1997) 11-17.

[2] A.Yu. Stakheev, L.M. Kustov, Appl. Catal. A 188 (1999) 3-35.

[3] R.A. Dalla Betta, M. Boudart, in: Proc. 5th Int. Congress Cat., 1973, pp. 1329-1341.

[4] T.M. Tri, J. Massardier, P. Gallezot, B. Imelik, Stud. Surf. Sci. Catal. 11 (1982) 141-148.

[5] C. Besoukhanova, J. Guidot, D. Barthomeuf, J. Chem. Soc., Faraday Trans. I 77 (1981) 1595-1604.

[6] A. de Mallmann, D. Barthomeuf, Stud. Surf. Sci. Catal. 46 (1989) 429. 
[7] A. de Mallmann, D. Barthomeuf, J. Chim. Phys. 87 (1990) 535-538.

[8] Z. Zhang, T.T. Wong, W.M.H. Sachtler, J. Catal. 128 (1991) 13-22.

[9] B.L. Mojet, J.T. Miller, D.E. Ramaker, D.C. Koningsberger, J. Catal. 186 (1999) 373-386.

[10] D.C. Koningsberger, J. de Graaf, B.L. Mojet, D.E. Ramaker, J.T. Miller, Appl. Catal. A 191 (2000) 205-220.

[11] D.C. Koningsberger, M.K. Oudenhuijzen, D.E. Ramaker, J.T. Miller, Stud. Surf. Sci. Catal. 130A (2000) 317-322.

[12] D.E. Ramaker, J. de Graaf, J.A.R. Van Veen, D.C. Koningsberger, J. Catal. 203 (2001) 7-17.

[13] A. Khodakov, N. Barbouth, Y. Berthier, J. Oudar, P. Schulz, J. Chem. Soc., Faraday Trans. 91 (1995) 569-573.

[14] V. Eskinazi, R.L. Burwell, J. Catal. 79 (1983) 118-131.

[15] B.F. Hegarty, J.J. Rooney, J. Chem. Soc., Faraday Trans. I 85 (1989) 1861-1871.

[16] T. Baird, E.J. Kelly, W.R. Patterson, J.J. Rooney, J. Chem. Soc., Chem. Commun. (1992) 1431-1433.

[17] S.M. Augustine, W.M.H. Sachtler, J. Catal. 106 (1987) 417-427.

[18] G. Fitzsimons, C. Hardacre, W.R. Patterson, J.J. Rooney, J.K.A. Clarke, M.R. Smith, R.M. Ormerod, Catal. Lett. 45 (1997) 187-191.

[19] M.K. Oudenhuijzen, S. van Dommele, J.A. van Bokhoven, D.C. Koningsberger, J. Catal. 214 (2003) 153-164.

[20] R. Pitchai, S.S. Wong, N. Takahashi, J.B. Butt, R.L. Burwell, J.B. Cohen, J. Catal. 94 (1985) 478-490.

[21] V. Ponec, G.C. Bond, Catalysis by Metals Alloys, in: Studies in Surface Science and Catalysis, Vol. 95, Elsevier, Amsterdam, 1995.

[22] C. Kemball, Adv. Catal. 11 (1959) 223-262.
[23] G.C. Bond, M.A. Keane, H. Kral, J.A. Lercher, Catal. Rev.-Sci. Eng. 42 (2000) 323-383.

[24] A.K. Galwey, Thermochim. Acta 294 (1997) 205-219.

[25] J.C.A.A. Roelofs, A.J. van Dillen, K.P. de Jong, Catal. Today 60 (2000) 297-303.

[26] M.K. Oudenhuijzen, J.H. Bitter, D.C. Koningsberger, J. Phys. Chem. B 105 (2001) 4616-4622.

[27] M.K. Oudenhuijzen, P.J. Kooyman, B. Tappel, J.A. van Bokhoven, D.C. Koningsberger, J. Catal. 205 (2002) 135-146.

[28] J.G. Tittensor, R.J. Gorte, D.M. Chapman, J. Catal. 138 (1992) 714 720.

[29] Ch. Baerlocher, W.M. Meier, D.H. Olson, Atlas of Zeolite Framework Types, Elsevier, Amsterdam, 2001.

[30] N.O. Gonzales, A.K. Chakraborty, A.T. Bell, Catal. Lett. 50 (1998) 135-139.

[31] G.N. Vayssilov, N. Rösch, J. Catal. 186 (1999) 423-432.

[32] R.J. Gorte, Catal. Lett. 62 (1999) 1-13.

[33] R.A. van Santen, G.J. Kramer, Chem. Rev. 95 (1995) 637-660.

[34] G.O.A. Janssens, B.G. Baekelandt, H. Toufar, W.J. Mortier, R.A. Schoonheydt, J. Phys. Chem. 99 (1995) 3251-3258.

[35] J. de Graaf, A.J. van Dillen, K.P. de Jong, D.C. Koningsberger, J. Catal. 203 (2001) 307-321.

[36] F.H. Constable, Proc. Roy. Soc. (London) A 108 (1925) 355.

[37] M. Temkin, Acta Physicochim. URSS 3 (1935) 312.

[38] W. Linert, R.F. Jameson, Chem. Soc. Rev. 26 (1989) 4977.

[39] D.C. Koningsberger, M.K. Oudenhuijzen, J. de Graaf, J.A. van Bokhoven, D.E. Ramaker, J. Catal. 216 (2003) 178-191. 